\title{
Immunological studies in a patient with ulcerative colitis and sarcoidosis ${ }^{1}$
}

\author{
DAVID W. WATSON, HAROLD M. FRIEDMAN, AND ALICIA QUIGLEY \\ From the Department of Medicine, University of Michigan Medical Center, Ann Arbor, Michigan, USA
}

SUMMARY This report describes a patient with both ulcerative colitis and sarcoidosis. This association is of interest because of the anergy for cellular immunity which was characteristic of the sarcoidosis and the cytotoxic effect of the patient's lymphocytes for allogenic colon epithelial cells which characterized the ulcerative colitis. This concordance of immunological findings suggests that the cytotoxic effect may have a basis other than cellular immunity.

The role of cellular immunity in the development of ulcerative colitis is uncertain although the conspicuous presence of lymphocytes in the affected tissues and the demonstration of a cytotoxic effect of circulating lymphocytes for colon epithelial cells has provided at least tangential evidence in support of this view (Perlmann and Broberger, 1963; Shorter, Spencer, Huizenger, and Hallenbeek, 1968; Watson, Quigley, and Bolt, 1966). On the other hand, the frequent presence of anergy for cellular immune reactions in patients with sarcoidosis is a well documented feature of this disorder (Isreal, 1965).

The simultaneous occurrence of ulcerative colitis and sarcoidosis is, therefore, more than curious and provides an opportunity for studying the presence of possible tissue-directed cellular immunity in a situation in vivo characterized by anergy for this type of immune response. The association of these two disorders has been reported previously (Trujillo, Halstead, and Ticktin, 1967; Jalan, MacLean, Ross, Sircus, and Butterworth, 1969) but no detailed studies of cellular immunity or the behaviour of lymphocytes from such a patient have been undertaken.

We would like to report a patient with well documented sarcoidosis and ulcerative colitis in whom a high degree of anergy for cellular immunity was nonetheless associated with lymphocyte cytotoxicity for human colon epithelial cells.

Received for publication 5 May 1971.

${ }^{1}$ Please address reprint requests to David W. Watson, Department of Internal Medicine, School of Medicine, University of California-Davis, Davis, California 95616.

\section{Case Report}

Patient M.K., a 52-year-old white housewife, was first admitted to the Detroit USPHS Hospital in March, 1965, with a 10-year history of intermittent lower abdominal cramping pain and occasional bloody diarrhoea.

Dyspnoea was first noted in 1952. By 1954 definite bilateral hilar adenopathy and fibrotic parenchymal changes were evident and a scalene node biopsy showed noncaseating granulomas (Fig. 1).

The only abnormal physical findings were dyspnoea at rest and generalized dry rales and rhonchi.

Laboratory data included a normal blood count, urinalysis, blood urea nitrogen, and serum calcium. Stool examinations were negative for ova and parasites and cultures revealed no enteric pathogens. Total serum protein was $8.1 \mathrm{~g}$ per $100 \mathrm{ml}(52.1 \%$ albumin, $1.6 \% \alpha_{1}$ globulin, $7.9 \% \alpha_{2}$ globulin, $12.1 \%$ $\beta$ globulin, and $26 \% \gamma$ globulin).

Sigmoidoscopy disclosed a friable granular mucosa and a mucosal biopsy was compatible with the diagnosis of ulcerative colitis. A barium enema showed loss of haustrations and mucosal ulcerations throughout the colon (Fig. 2).

\section{SPECIAL STUDIES}

The patient was seen in the gastrointestinal clinic of the University of Michigan Medical Center where the following special studies were carried out.

Serum immunoglobulin determinations showed an IgG of $2,225 \mathrm{mg}$ per $100 \mathrm{ml}$, an IgA of $385 \mathrm{mg}$ per $100 \mathrm{ml}$, and an IgM of $105 \mathrm{mg}$ per $100 \mathrm{ml}$. Serum protein immunoelectrophoresis was qualitatively 


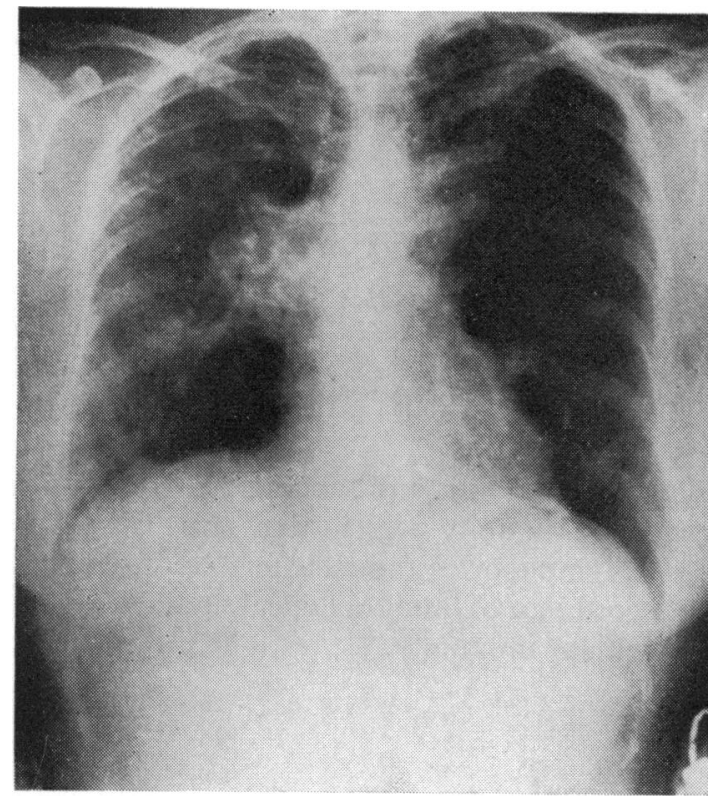

Fig. 1 Chest radiograph showing the hilar adenopathy and parenchymal scarring which characterized this state of the patient's sarcoidosis.

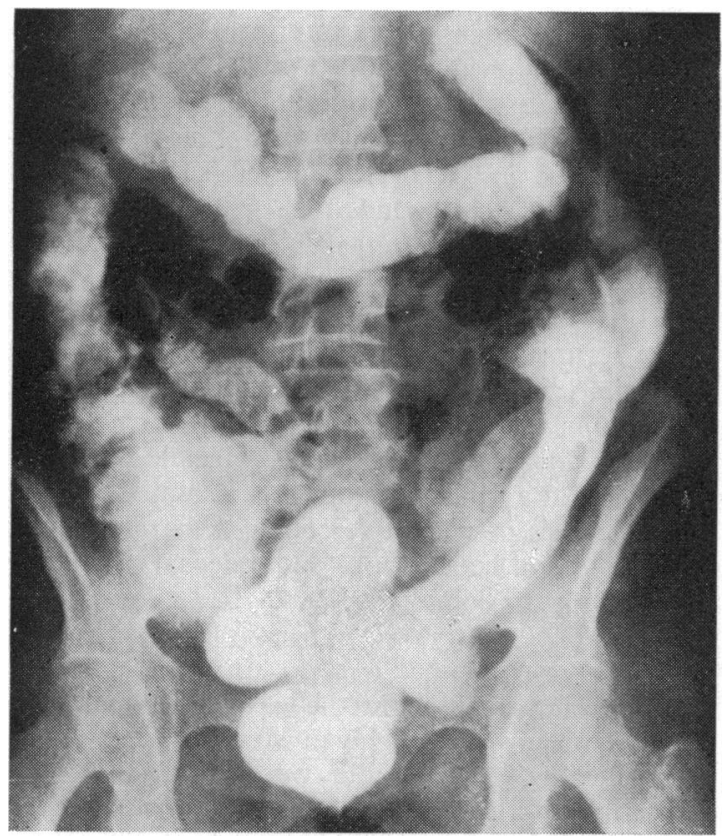

Fig. 2 Barium enema depicting loss of haustrations and mucosal ulceration compatible with the diagnosis of ulcerative colitis. normal. Mumps, histoplasmin, OT, and intermediate strength PPD skin tests were all negative at 24 and 48 hours. A Kveim test was histologically positive. Sensitization to $0.1 \mathrm{mg}$ of 2,4 dinitrochlorobenzene applied epicutaneously to the forearm could not be achieved and the tuberculin reaction failed to convert after the intradermal administration of $0.1 \mathrm{ml}$ of BCG vaccine (Glaxo Laboratories). Six weeks after BCG vaccination the patient's lymphocytes were injected into a tuberculin-negative recipient who had demonstrated the capacity to react to 2,4 dinitrochlorobenzene. His tuberculin reaction also failed to convert.

A lymphocyte suspension was prepared from the patient's peripheral blood by the sedimentation method of Bach and Hirschhorn (1964) and an autologous leucocyte skin test carried out. The response was positive at 24 hours, exhibiting $2 \mathrm{~cm}$ of induration. These lymphocytes were also demonstrated to be cytotoxic for allogenic colon epithelial cells. The methods utilized in carrying out these cytotoxicity studies have been reported in detail elsewhere (Watson et al, 1966).

\section{Discussion}

The present case manifests a majority of the accepted criteria for a diagnosis of sarcoidosis. Similarly the diagnosis of ulcerative colitis was based upon characteristic sigmoidoscopic, radiological, and histological findings.

The significance of the concurrence of these two disorders is related to the abnormalities of lymphocyte function with which each has been associated.

In sarcoidosis this functional abnormality is manifested by anergy for cutaneous cellular immune responses and hyporesponsiveness of lymphocytes to mitogenic stimulation (Cowling, Quaglino, and Barrett, 1964; Buckley, Nagaya, and Sieker, 1966).

In the case of ulcerative colitis and Crohn's disease, peripheral lymphocytes have been shown to be cytotoxic for allogenic colon epithelial cells (Perlmann and Broberger, 1963; Watson et al, 1966; Shorter et al, 1968). This effect exhibits a high degree of tissue and disease specificity and is present in virtually all patients with either of these two disorders. The nature of this cytotoxic effect is presently not known.

Because lymphocytes play a central role in cellular immune reactions, especially those involving tissue destruction or alteration, eg, contact dermatitis, allograft rejection, experimental autoallergic disorders, and graft-versus-host reactions, it is reasonable to postulate that the cytotoxic effect on the colon epithelial cells has a similar basis. The present case presents evidence suggesting that the 
basis for this cytotoxic effect of lymphocytes for colonic epithelial cells does not reside in a cellular immune mechanism, namely, the occurrence of such an effect in a patient demonstrated to have a high degree of anergy for this type of immunological response.

Certain qualifications, however, are necessary. Only the present case provides any information concerning this relationship. In the case of two disorders as variable as sarcoidosis and ulcerative colitis it is quite possible that any studies carried out at a particular point in time might not find general applicability to the overall course of either or both diseases. Secondly, the anergy which so often characterizes patients with sarcoidosis may not extend to all antigens. It is conceivable that tissue antigens might be less affected by this anergic state than the usual exogenous antigens employed to demonstrate such anergy. The positive autologous leucocyte skin test would tend to support this possibility.

On the other hand, one might interpret the relatively benign course of this patient's inflammatory bowel disease as being due to the supervention of such a state of anergy with a diminution in the cytotoxic effect of the lymphocytes for the colon epithelial cells. This question, of course, is impossible to answer: With regard to this possibility it is of interest that this patient's lymphocytes did not exert a cytotoxic effect on the colon cells until after five hours of contact compared with the usual two hours seen in all other patients with chronic inflammatory bowel disease.
Although no conclusion regarding the nature of the cytotoxicity of peripheral lymphocytes for colon epithelial cells in chronic inflammatory bowel disease can be based upon the findings in the present case, it nonetheless does suggest that this effect may not be related to a state of cellular sensitivity.

\section{References}

Bach, F., and Hirschhorn, K. (1964). Lymphocyte interaction: A potential histocompatibility test in vitro. Science, 143, 813-814.

Buckley, C. E. III, Nagaya, H., and Sieker, H. O. (1966). Altered immunologic activity in sarcoidosis. Ann. intern. Med., 64, 508-520.

Cowling, D. C., Quaglino, D., and Barrett, P. K. M. (1964). Effect of Kveim antigen and old tuberculin on lymphocytes in culture from sarcoid patients. Brit. med. J., 1, 1481-1482.

Isreal, H. L. (1965). Sarcoidosis. In Immunological Diseases, edited by M. Samter, pp. 406-417. Little, Brown, Boston.

Jalan, K. N., MacLean, N., Ross, J. M., Sircus, W., and Butterworth, S. T. G. (1969). Carcinoma of the terminal ileum and sarcoidosis in a case of ulcerative colitis. Gastroenterology, 56, 583-588.

Perlmann, P., and Broberger, O. (1963). In vitro studies of ulcerative colitis. II. Cytotoxic action of white blood cells from patients on human fetal colon cells. J. exp. Med., 117, 717-733.

Shorter, R. G., Spencer, R. J., Huizenga, K. A., and Hallenbeck, G. A. (1968). Inhibition of in vitro cytotoxicity of lymphocytes from patients with ulcerative colitis and granulomatous colitis for allogeneic colonic epithelial cells using horse anti-human thymus serum. Gastroenterology, 54, 227-231.

Trujillo, N. P., Halstead, L. S., and Ticktin, H. E. (1967). Chronic ulcerative colitis, xanthomatous biliary cirrhosis and sarcoidosis. Med. Ann. D. C., 36, 170-174.

Watson, D. W., Quigley, A., and Bolt, R. J. (1966). Effect of lymphocytes from patients with ulcerative colitis on human adult colon epithelial cells. Gastroenterology, 51, 985-993.

Watson, D. W., and Bolt, R. J. (1968). Immune mechanisms and ulcerative colitis. In Progress in Gastroenterology, edited by G. B. J. Glass, pp. 391-411. Grune and Stratton, New York.

Williams, W. J. (1965). A study of Crohn's syndrome using tissue extracts and the Kveim and Mantoux tests. Gut, 6, 503-505. 